\title{
Where have all the parties gone? Fraenkel and Grofman on the alternative vote - yet again
}

\author{
Donald L. Horowitz
}

Received: 18 October 2006 / Accepted: 29 November 2006 / Published online: 16 August 2007

(C) Springer Science + Business Media B.V. 2007

\begin{abstract}
The alternative vote (AV) is a preferential electoral system that tends to reward political moderation and compromise. Fraenkel and Grofman (2004, 2006a, 2006b) have repeatedly attempted to show that $\mathrm{AV}$ is not conducive to interethnic moderation in severely divided societies. In this response to their latest attempt, I point out that neither political party coordination of the vote nor strategic voting plays any part in their analysis. In contrast, I explain how moderate parties of one ethnic group are able to induce their supporters to cast ballots for moderate parties supported by voters of another ethnic group. I also explain why the incentives for parties to arrange interethnic vote transfers are much greater under AV than they are under systems such as the single transferable vote, which is in use in Northern Ireland, and I show that Fraenkel and Grofman's interpretations of AV's operation in Australia, Fiji, Sri Lanka, and Papua-New Guinea are contrary to the evidence.
\end{abstract}

By attempting to model voter behavior and by analyzing the use of the alternative vote in Fiji, Fraenkel, and Grofman (2004, 2006a) have twice challenged the connection I have postulated between $\mathrm{AV}$ and interethnic moderation. I have had the opportunity to reply briefly to each of these articles (Horowitz, 2004, 2006). In the most recent iteration, the coauthors also published a brief rejoinder to my reply (Fraenkel \& Grofman, 2006b). Yet they claim there is still more they need to say but were unable to say last time. ${ }^{1}$ On the other hand, at the conclusion of the article published in the current issue, they contend that in 2004 they had already dealt a death-blow to my claims for AV and that nothing I have "written since in any way rebuts it" (2007: 9). If so, what is the rationale for the article in this issue?

\footnotetext{
${ }^{1}$ In their latest rejoinder, Fraenkel and Grofman (2006b: 664 n. 1) state the following: "A longer version of this article, including responses to Horowitz's more general points about interethnic transfers of preferences, strategic voting, and evidence regarding promoderation impacts of alternative vote (AV) from elsewhere in the world, is available from the authors." It is a fair inference that the article in this issue and that longer, unpublished version of the rejoinder in Comparative Political Studies are one and the same, now retrieved from the cutting-room floor.
}

D. L. Horowitz

Duke University, USA

e-mail: dhorowitz@law.duke.edu 
There is reason to think the statement just quoted is merely a rhetorical flourish, for Fraenkel and Grofman have now gone to considerable trouble to elicit new material favorable to their case, including "personal communications" from people who agree with them. Yet, the new material provides no killer argument they have missed previously. It does, however, provide a welcome opportunity to open some new windows on the issues at stake. To keep this response as brief as possible and to avoid undue repetition, I shall minimize references to the literature, and I refer the reader to my two previously published replies (Horowitz, 2004, 2006), but first I provide a quick summary of where the debate stands so far.

Fraenkel and Grofman (2004) began by attempting to formalize the assumptions of the theory that connects AV to interethnic accommodation. They did this by modeling voter behavior in several hypothetical electoral constituencies. In my reply to that article, I showed that their effort to model voter behavior under AV in divided societies bears no relationship to the theory of interethnic accommodation it purports to test (Horowitz, 2004). Two of their three models transfer each and every voter's second and subsequent preference to a party of the voter's own ethnic group before transferring a single preference to a party from another ethnic group. This is hardly a test of a theory based on the willingness of voters to transfer second and subsequent preferences across group lines. ${ }^{2}$

It is always possible to lay out a set of unlikely assumptions about voter behavior under which an electoral system produces odd results. This applies to all electoral systems, not just AV. In such cases, the explanation for the results is simply embedded in the unlikely assumptions. The results are, in other words, essentially tautological.

Fraenkel and Grofman's second article (2006a) was an exploration of the results of AV in Fiji, which adopted the system for its 1999 election. In my response to that article, I noted that Fraenkel and Grofman's attempt to show that AV will not "necessarily" and "uniformly" produce moderate results refutes a proposition that has not been advanced, for proponents of AV speak only of tendencies arising out of its incentive structure (Horowitz, 2006). I also showed that their examination of the results of Fiji's elections was based on perverse interpretations of the data and a serious underestimate of the extent to which the strategic behavior of voters can support interethnic moderation. Hence the title of my reply: "Strategy Takes a Holiday."

In this response to Fraenkel and Grofman, I begin with an explanation of the electoral underpinnings of interethnic moderation, emphasizing the role of political parties in guiding their supporters toward strategic voting across group lines and underscoring the absence of parties and strategic behavior in Fraenkel and Grofman's account. I then turn to the specifics of their critique of my previous responses, rebut their inapt efforts to model voter behavior under $\mathrm{AV}$, demonstrate that my statements about voter behavior have (contrary to their assertions) been consistent over a very long time, and respond to their curious interpretations of electoral processes and results in Northern Ireland, Australia, Fiji, Sri Lanka, and Papua-New Guinea. Northern Ireland is the only case where Fraenkel and Grofman's interpretation of the empirical evidence seems at first to be plausible, but, as I shall show, the incentives of Northern Ireland's electoral system for ethnic moderation are completely different from those of AV. I conclude with a brief discussion of the modest but important part that electoral innovation can play in fostering interethnic accommodation.

\footnotetext{
${ }^{2}$ In one case in which Fraenkel and Grofman transferred some second preferences interethnically, their exercise showed that moderate parties could win even if majorities of both groups preferred extremists of their own groups to moderates and even if supporters of the moderate party eliminated at the first count transferred more of their second preferences to extremists of their group than to moderates of other groups. As I pointed out, this result is favorable to the moderating propensities of AV (Horowitz, 2004: 511).
} 


\section{The mechanisms of moderation}

If the alternative vote works for interethnic moderation, then the mechanism must be interethnic vote transfers. A basic understanding of ethnic politics in severely divided societies - those characterized by the salience of ethnicity in politics and the presence of intergroup antipathy - makes it clear why this is so. In such societies, there is, in the first instance, an ethnically segmented market for votes. That is, parties representing Group A compete among themselves for the votes of voters from Group A and cannot compete directly with parties of Group B for Group B votes. In a preferential electoral system, it follows that first preferences will generally be cast intraethnically. The intraethnic party competition for those first-preference votes makes it difficult, although not always impossible, for a party representing Group A to ask Group A voters to support it, rather than another A party, as the most vigorous and authentic representative of $\mathrm{A}$ interests and simultaneously to ask those same voters to cast second preferences for the other A party that it has disparaged as a less vigorous and authentic representative of A interests. I repeat, however, that this is a probabilistic matter, not a logical impossibility. ${ }^{3}$

The same is not true when it comes to the interethnic exchange of second and subsequent preferences. In a single-member constituency that Party Al is unlikely to win because the constituency is dominated by voters of Group B, it becomes possible for Party Al to urge its supporters to cast second preferences for Party B1, provided that Party Bl can be depicted as a better choice from the standpoint of Group A's interests than Party B2, depicted as more extreme in its anti-A orientation. This I call sponsorship of candidates of one group by a party of another.

Furthermore, if Party Al and Party Bl make recurrent exchange agreements of this kind and agree before the election to form a coalition, then Party Al can make the argument to A voters that, in a Group B-dominated constituency, their support for a Party Bl candidate actually advances the ability of Party $\mathrm{Al}$, which is their preferred party, to form or participate in a coalition government. In a constituency that is composed in such a way that the failure of Party Al supporters to vote for a Party Bl candidate will result in the victory of the candidate of extremist Party B2 or the candidate of a rival A party, the interest of Party Al in promoting the $\mathrm{B} 1$ candidate will be palpable and easily understood by supporters of Party Al. Precisely such appeals have been made, in favor of interethnic coalition candidates and against intraethnic rivals, under diverse electoral systems in countries as varied as Malaysia, Papua-New Guinea, Lebanon, and Fiji. In the field, I have witnessed such appeals.

The underpinning of such agreements to pool votes across group lines is a reciprocal commitment to interethnic moderation. It would be very difficult for Party Al to sponsor candidates of Party B1, or vice versa, if the sponsoring party could not credibly claim to its own supporters that the candidates for whom votes are sought are appropriate allies, people who, although ethnic strangers, are not antagonistic to the interests of the ethnic group of the sponsoring party. It would be even more difficult to form a preelectoral coalition with a party representing a different ethnic group in a severely divided society unless the coalition partners have committed themselves to some degree of interethnic compromise. Coalitions of the extremes have been attempted in some such societies, but they readily fall apart.

In this account, the role of party leaders in directing their followers is vitally important. Any adequate inquiry into the propensities of an electoral system needs to incorporate possibilities

\footnotetext{
${ }^{3}$ In addition to the difficulty of urging Group A voters to cast first-preference votes for Party $\mathrm{Al}$ and simultaneously asking them to cast second-preference votes for Party A2, there is the problem of urging voters to vote at any level of preference for the party's most direct rival.
} 
for strategic behavior by voters and coordination of the vote by political parties. Parties are able to assess opportunities afforded by the electoral system to enhance their success at the polls by making vote-pooling arrangements across ethnic lines, making appropriate adjustments to their positions on ethnic issues if the opportunity structure so dictates, and directing votes of their supporters accordingly.

The role of political parties as coordinators of the vote comes into play in myriad situations, not merely in making interparty agreements to exchange votes or directing vote transfers in preferential systems, although it is assuredly present there. ${ }^{4}$ In Australia, as in Fiji, the vast majority of voters follow parties' recommendations of the preference order in which to cast their ballots (Jaensch \& Mathieson, 1998: 15-16; Bean, 1997). In Northern Ireland's single transferable vote system, recent elections "show an increasing sophistication in vote management exercised by the parties" (Elliott, 2003: 16). Yet neither the strategic behavior of voters nor the coordination of the vote by parties is present in Fraenkel and Grofman's treatment. ${ }^{5}$ In their analysis, interparty agreements to exchange preferences are nowhere to be found. Voters are considered implicitly to be ethnically self-interested individual actors, who transfer their votes sincerely and without party guidance about where ethnic interests lie. Parties as intermediaries between voters and their preferences-a role that parties will quickly seize, as they did in Fiji (see Horowitz, 2006: 656), if a preferential system is adopted-do not figure in Fraenkel and Grofman's calculations. That is why they can consider three different electoral possibilities, without assigning probabilities to them: (1) centrifugal, involving moderate voters whose second preferences "gravitate towards those offering a hardline assertion of ethnic interests" (Fraenkel and Grofman, 2007: 3); (2) centripetal, involving voters who move to the moderate center, either across group lines or intraethnically, from extremists to moderates of the same group; or (3) erratic and unpredictable results, when other issues and cleavages intervene to confound ethnic issues and cleavages. I shall deal with these in inverse order of their probability.

The third possibility, of multiple cleavages, apart from those associated with ethnic conflict, that confound interethnic vote exchange and so fail to favor moderation, is not worthy of much attention. In severely divided societies, such competing lines of cleavage are not likely to trump the ethnic cleavage. If they do, then the conflict is unlikely to be dangerous enough to require any electoral engineering. AV has not been recommended for such societies.

The first, centrifugal possibility does not square with ethnic politics, for reasons already adduced. Moderate Party Al is unlikely to direct second preferences of its supporters to extremist Party A2 and so reduce its own chances of representing the As in the government that is to be formed.

I do not mean to suggest that there are literally no Al voters who cannot stomach casting a ballot for any B candidate and who will therefore prefer even an A2 candidate in the face of a contrary recommendation from their preferred party, Al. There are such voters, and where they predominate ethnic politics can become polarized. But their numbers are generally limited in severely divided societies by two conditions: (1) Intraethnic cleavages divide supporters

\footnotetext{
${ }^{4}$ The coordinating role of parties is also important across electoral systems, in instructing supporters in how to vote when the party itself cannot win a constituency or is not running a candidate there; or how to vote in a runoff when the party's candidate has come in third in the first round; or how to vote in an election conducted under the single non-transferable vote when the party is running multiple candidates of varying popularity in a single constituency and needs to spread votes in order to maximize its share of seats. See, e.g., Moon, 1997.

${ }^{5}$ I have analyzed the absence of strategic voting in Fraenkel and Grofman's models in Horowitz, 2006: 653-55. Here I focus more on the curious absence of parties in their account and the difference this makes to the outcome.
} 
of rival parties $\mathrm{Al}$ and $\mathrm{A} 2$ and inhibit the crossover between them. ${ }^{6}$ (2) Very often, in divided societies, voters regard ethnic interests as synonymous with those of the ethnic party they support and so are willing to be guided by that party. For example, in open seats in Fiji (seats in which Fijian and Indian candidates could compete) in 1999, more than 80 percent of second preferences were cast across ethnic lines. The willingness of voters to follow party guidance is what usually makes interethnic vote exchange a profitable transaction.

The second possibility listed by Fraenkel and Grofman actually consists of two different possibilities: one a second or subsequent preference for a moderate candidate of another ethnic group, the other a transfer from an extremist to a moderate candidate of the same group. Both possibilities, it should be emphasized, are conducive to interethnic moderation, but the former is more likely than the latter. Intraethnic party competition makes interethnic coalitions attractive where votes can be exchanged across group lines, and the alternative vote makes such exchanges more exigent if a candidate is to achieve the 50 percent plus one needed to win. If parties need such transfers to maximize their electoral possibilities, they will be apt to arrange for them. If they do not, as we shall see, they will not.

It will be noted that the underlying mechanism of interethnic vote pooling is by no means peculiar to the alternative vote. It is simply that, by requiring 50 percent plus one to win a seat, AV makes such vote pooling attractive in a split field in which no candidate is assured of a majority of first preferences. ${ }^{7}$ As I have already mentioned, however, the same mechanism may be invoked in multiparty contests with heterogeneous constituencies even under firstpast-the-post. That is the same mechanism that underlay the Lebanese system of ethnically reserved seats with common-roll elections in multimember constituencies (for an elaboration, see Baaklini, 1976: 141-154) and the single list for the Presidential Council proposed in the Annan Plan for Cyprus (see Annan, 2004: 10). Similarly, marginal dependence on the votes of voters from groups other than one's own forms the basis for interethnic moderation when territorial distribution of the vote is required for election and where territory is a proxy for ethnicity, as in the relatively recently enacted requirements for presidential elections in Indonesia. Other systems can also be devised to make use of the same mechanism. Where $\mathrm{AV}$ is not appropriate, therefore, there may still be ways to utilize the electoral system to foster intergroup accommodation.

\section{The newest critique and the reply}

With this background, it is possible to assess the particulars of the latest Fraenkel and Grofman critique. I shall deal with their main points in short, numbered subsections.

\subsection{The modeling exercise redux}

Fraenkel and Grofman (2004) model three cases of elections under AV. As mentioned earlier, in the first two of these, they transfer no preferences interethnically until it is no longer possible to transfer a preference intraethnically (Fraenkel \& Grofman, 2004: 495, 496). Obviously,

\footnotetext{
${ }^{6}$ By intraethnic cleavages, I mean principally ascriptive differences, such as those deriving from religion, caste, dialect, or region of origin that divide a group into subgroups that often support different parties representing the same ethnic group (see Horowitz, 2000a: 350-353), but class differences may also underpin intraethnic party differentiation.

${ }^{7}$ By split field, I mean to imply that if there is only one party per group, vote pooling under AV does not come into play.
} 
such models have no bearing on the validity of a theory postulating interethnic preference transfers at the earliest possible point. In the third case, when they transfer a minority of an excluded party's votes interethnically, the moderate candidate of the other group wins (Fraenkel \& Grofman, 2004: 497). I have analyzed this modeling exercise previously in this journal (Horowitz, 2004: 509-11). Nothing they have added here shows how their exercise reflects badly on AV's propensity to foster moderation when second preferences are exchanged interethnically. The models have the same deficiencies they had when originally published in this journal in 2004.

\subsection{Voter behavior under AV}

Fraenkel and Grofman (2007) contend that, in my earlier replies to them, I have changed my long-held assumptions about voter behavior in severely divided societies. According to them, I have not previously acknowledged that the utility of AV depends on the willingness of voters to cast second and subsequent preferences interethnically even before all intraethnic choices are exhausted. The truth is rather different. The phrase I have habitually used for interethnic preference exchange, going all the way back to the first time I discussed AV in 1989 (Horowitz, 1989: 23; 1990: 127; 1991: 189, 193, 201; 2000b: 269) is "second preferences" or "second and third preferences." Later, I used the phrase "second and subsequent preferences" (Horowitz, 2003: 123). "Second" means directly following the preference for a voter's (first) preferred party, and the mechanism I cited in 1989, and have cited consistently since then, is an agreement between moderate parties of different ethnic groups to pool votes across group lines, in order to defeat ethnic extremists. There is nothing new here. If Fraenkel and Grofman understood something different from my prior statements, theirs was, to say the least, a perverse and idiosyncratic reading.

\subsection{Ethnic voting and vote transfers}

Fraenkel and Grofman (2007) are quite correct that, in severely divided societies, voters will prefer candidates and parties of their own ethnic group, as I have already said. As I have written many times, ethnic voting is common in such societies (see, e.g., Horowitz, 2000a). That is why altering the incentive structure is so important.

Correctly, too, they point out that, in Northern Ireland under the single transferable vote (STV), interethnic preference exchanges have been rare (Fraenkel and Grofman (2007)). But here is the rub: Although STV and AV are considered to be, respectively, multimember and single-member variants of the same system, for purposes of interethnic accommodation STV is a very different system from AV. In Northern Ireland under STV, it takes only 14.3 percent of the vote to win a seat. ${ }^{8}$ Knowing this, parties understand that they can win seats on the first preferences of voters of their own group. To the extent they can do this, it comes as no surprise that Northern Ireland parties generally do not make agreements to transfer votes across the ethnic divide. Once again, the crucial mediating role of parties is missing in the Fraenkel and Grofman analysis.

Moreover, AV elections are conducted in single-member constituencies, whereas parties run multiple candidates in STV's multimember constituencies, and so they have every reason to ask their supporters to transfer second and subsequent preferences to other candidates of the same party in the same constituency. This is precisely what happens with the vast majority

\footnotetext{
${ }^{8}$ That is because there are six seats to each constituency, and the quota for victory is $\frac{1}{(\text { Number of Seats }+1)}+1$. 
of vote transfers in Northern Ireland. They go to other candidates of the same party, as the very source cited by Fraenkel and Grofman points out (Elliott, 2003). In the most recent Northern Ireland Assembly elections, "When the main parties have candidates still running, between 80 and 90 percent of transfers remain within the party" (Elliott, 2003: 16). This reflects, says Elliott, the parties' strong role, consisting of "vote management tactics" to keep preference transfers directed toward candidates of the same party.

There is also, however, in Northern Ireland an interesting category of "terminal transfers," the minority of cases when candidates from the same party are no longer present. In 2003, most of these were within the same ethnic bloc - and, in the absence of interparty agreements, this is predictable - but the rate was highly variable. In four contests where no moderate Catholic-party candidate was available to receive transfers from those who had voted for such candidates earlier, as many Catholic transfers went to an interethnic party or to the moderate Protestant party as went to the extreme Catholic party (Elliott, 2003: 16). Despite the weak structure of incentives to interethnic moderation under STV and without interparty agreements, interethnic vote transfers occur, to the detriment of extremists, even when there are intraethnic alternatives possible. ${ }^{9}$ Still, the overall tendency is for ballots to be cast intraethnically.

Contrast the incentive structure of AV. Under AV, (1) parties run only one candidate each, since candidates stand for election in single-member constituencies, and (2) it requires 50 percent plus one (not 14.3 percent) to win a seat. Accordingly, under AV, (1) there is no possibility of transferring preferences to other candidates of the same party, and (2) it is far more difficult to win a seat on the votes of one's own group, so the incentives to cooperate across party and group lines in order to secure second and subsequent preferences are much greater. The Fraenkel-Grofman comparison of AV and STV is, therefore, completely misplaced.

Equally unfounded is the casual assertion that the incentives of AV and first-past-the-post are "exactly the same" (Fraenkel and Grofman, 2007: 5). Take the case of a likely plurality leader (or, more properly, the party with recurrent plurality leaders) on first preferences in an AV election, who would be the winner of that seat if the election were conducted under first-past-the-post. The plurality leader in an AV election is not likely to believe the incentives of the two systems are the same or to sit supine on the assumption that they are the same. If the plurality leader has the strong support of his or her own first-preference voters but has not sought second and subsequent preferences from supporters of other parties, the failure to do so may result in defeat, as indeed it has for candidates in this position in Australia (Johnson, 1984). ${ }^{10}$ This is one way in which AV works against uncompromising, extreme candidates.

\footnotetext{
${ }^{9}$ The test of interethnic terminal transfers is weaker on the Protestant side in 2003, because in all eight cases of terminal transfers from supporters of the moderate Protestant-party candidate there were no candidates of the extreme Protestant party left to receive them. Because of the absence of intraethnic alternatives, the large number of transfers to the moderate Catholic party in those cases has less significance, although Elliott (2003: 16) suggests a conscious effort by moderate Protestant-party leaders to help the moderate Catholic party.

${ }^{10}$ Or consider the case of Papua-New Guinea, discussed below, where candidates under first-past-the-post have often won seats on very small pluralities - sometimes on a total vote of under 20 percent, based on support from their own group alone. Will such candidates not understand immediately that the shift of the PNG electoral system back to AV changes their incentives and requires them to seek support outside their own group? Certainly, such a change of incentives is what those who designed and endorsed the shift back to AV envisioned. Reilly, 2002.
} 


\subsection{The comparative evidence}

When they come to the comparative evidence on AV, Fraenkel and Grofman (2007: 7-8) have several strategies. It is worth reviewing each briefly in turn.

For Australia, they accept the view of a few dissenters - some of whom are well-known proponents of proportional electoral systems - that AV does not really promote moderation. This is by no means the dominant view in the literature (see Reilly, 2001: 44-46; Bean, 1986; Graham, 1962; see also Marks \& Bean, 1992: 111).

For Fiji, Fraenkel and Grofman persist in the view that the wrong - that is, the immoderate - interethnic coalition won in the first AV election conducted there in 1999, in spite of strong evidence that the electorate viewed the winning coalition as the moderate one. In that election, most Indo-Fijian voters saw the Fijian partner in the losing coalition, asserted by Fraenkel and Grofman to be the moderate one, as anti-Indian. After all, the leader of that party, the sitting prime minister, had earlier promulgated a constitution so discriminatory against Indians that it provoked international outrage. On the other side, Fijian parties in the winning coalition had longstanding ties to the winning Indian party. Fraenkel and Grofman offer no response to any of this evidence. They simply think the winning coalition was the wrong one and label it a "coalition of opposites" (see Horowitz, 2006: 656-57).

There is a more general point here pertaining to the ability of electoral systems to induce moderate behavior. Fraenkel and Grofman suggest that, in spite of the prime minister's anti-Indian history, the losing coalition in Fiji in 1999 was more moderate because it had subsequently taken steps to produce the new constitution that contained the AV system, and it had expected to benefit from that system. They also stigmatize the Indo-Fijian leader of the winning coalition as an extremist, because he came late to interethnic coalition politics as a result of AV. And in this they miss the very point of the incentives theory of interethnic accommodation. Interethnic moderation is not some genetic attribute of a political party. If ethnic politics is to be moved in a more conciliatory direction, the incentives should induce and reward conciliatory behavior, even where it did not exist previously. Moderation or extremism is not forever encoded in the DNA of politicians or their party. It is a function of behavior, which is, in part, a function of incentives.

When it comes to their treatment of Sri Lanka, which adopted a version of AV for presidential elections, Fraenkel and Grofman engage in what might be called, generously, a curious interpretation of the facts. The first presidential election under the new system took place in 1982, but by then a barrage of legislative and executive action had essentially told the Tamils in no uncertain terms that they were, at best, second-class citizens. Tamils boycotted altogether the first elections conducted under that system and under a proportional system for the legislature. The electoral system had nothing to do with the boycott. A year later, legislators from the leading Tamil party were expelled from parliament for refusing to take an oath renouncing separatism. By then a civil war had started and has not been settled yet, so it is scarcely surprising that the boycott continues. Fraenkel and Grofman imply that this history somehow counts against AV's propensity to moderate conflict. I conclude instead that AV has not had a test of its propensity to induce moderation in Sri Lanka. In this, I am not alone (see Reilly, 2001: 120-124; Sisk, 1996: 61). No fair reading of the evidence would support a different interpretation.

Finally, there is Papua-New Guinea (PNG), where Fraenkel and Grofman attribute intergroup conflict to a host of social and institutional variables apart from the electoral system. They also note that PNG political leaders are not relying only on an electoral-system change back to AV to restore a modicum of civil peace. None of this diminishes the role of the electoral system in helping to push politics toward conflict or accommodation. If Fraenkel and Springer 
Grofman want to make a claim that the electoral system is always neutral on this score, that really would be new, but nothing they have said provides support for such a claim. Merely because the electoral system does not determine everything does not mean that it determines nothing.

In Papua-New Guinea, there is abundant evidence that interclan conflict was mitigated by the need for candidates to secure support from multiple clans in order to reach the 50 percent threshold, when AV was in force before independence. Preference-exchange agreements were abundant, and accommodation of groups claims was the result (Reilly, 2001: 58-94; Wolfers, 1968).

As soon as AV was replaced by first-past-the-post elections, it was possible to win election on small pluralities, and interclan tension grew, even during the very first non-AV election (Premdas, 1978: 79-80). Reilly, who is a real expert on Papua-New Guinea, finds (2001: 93-94) that AV provided in PNG

clear centripetal incentives towards cross-ethnic bargaining, multi-ethnic coalitions, and inter-ethnic moderation. When these incentives were removed, and political actors were faced with a different set of strategic assumptions, their behaviour changed accordingly. The result has been increasing levels of violence, increasingly unrepresentative members of parliament, a fragmenting party system and decreasing overall prospects for the consolidation of democracy in Papua New Guinea. It would be hard to find a clearer example of the importance of political institutions in general, or the case for centripetal strategies of institutional design in particular.

What do Fraenkel and Grofman (2007: 8) find? A mix of unconnected factors.

\section{Electoral systems, institutions, and probabilities}

The cases of Sri Lanka and Papua-New Guinea illustrate points I have made many times over: Timing is important; changes in institutional structures before conflict has become violent are much more likely to facilitate conciliatory results than are changes that occur after polarization has become embedded (see, e.g., Horowitz, 1989). Fraenkel and Grofman's acknowledgment that AV may have conflict-mitigating potential in severely divided societies without a history of civil war (2007: 3) blinks in the same direction, and it leads me to wonder exactly what their ultimate claim is.

The electoral system may be the institution most amenable to manipulation in the quest for structures that foster intergroup accommodation, but it is part of a total institutional configuration, some other parts of which may encourage conflict behavior. Sometimes the marginal effects of electoral engineering make the difference between civil peace and warfare; sometimes, not. We are in the realm of tendencies and probabilities here, and Fraenkel and Grofman's attempts to take a few quotations out of context and make it appear as if I advocate cookbook electoral recipes for intergroup harmony are belied by the corpus of my work, which argues that ethnic conflict is a generally difficult problem and that those who think they have a formula for reversing or abolishing it altogether are deluding themselves (see Horowitz, 2000a: 564-568). No reader who reads this body of work even cursorily will credit their reading.

Fraenkel and Grofman (2007: 2) say I "continue to push for" adoption of AV. I certainly do "continue to push for" electoral systems and other institutions, such as federalism and regional devolution, that can provide incentives to accommodative behavior. Depending on the context, AV or some other system may or may not be among the approaches that could 
prove useful in modifying the political incentive structure. Papua-New Guinea has indeed repealed first-past-the-post and returned to AV. After its civil war, Lebanon chose again its distinctive, conciliatory electoral system of reserved seats, multimember constituencies, and common electoral rolls. Indonesia has adopted a regional-distribution formula for presidential elections. So, centripetal electoral engineering is very much alive, but no such approach should be seen as the universal solvent - or, indeed, as a solvent at all - for ethnic conflict. The object is to reduce the level of conflict and to encourage intergroup compromise, not to overcome ethnic differences altogether.

\section{Electoral innovation and conflict reduction}

Even in severely divided societies, a great deal of electoral innovation responds, either consciously or not, to goals other than interethnic accommodation. Many policymakers believe the essential choice is between plurality and proportional systems, and they often prefer proportional results, even though proportional systems tend to replicate or even amplify existing cleavages, rather than moderate them. Others, concerned about the domination of party leaders who set the order of candidates on lists for national PR systems, prefer constituency-based systems that give more voice to voters, whether those systems are plurality, constituency-list, or STV. Where the inquiry begins has a great deal to do with the system that is adopted.

Where, however, the inquiry explicitly begins with the desire to find a system that will moderate conflict behavior, it is striking that those who conduct the inquiry frequently turn to the same mechanism of marginal dependence for electoral success on voters other than one's own. In Bosnia in the late 1990s, when the behavior of ethnic extremists had prompted a search for systems to support moderates, no fewer than three careful outside proposals for a new electoral system were submitted (International Crisis Group, 1998, 1999; DeBorda Institute, 1998). Each was based on a design that required candidates to court voters outside their own ethnic group. There would have been implementation problems with each, but it was striking that all three authors understood the task of conciliating the Bosnian conflict in the same way. ${ }^{11}$

There is now some serious quantitative evidence that this understanding is correct. Steven Wilkinson (2004) has recently shown that anti-Muslim violence is significantly less frequent and severe in those Indian states in which the ruling party is, at least in part, dependent on Muslim electoral support than it is in states in which it is not. Fearful of losing that support, ruling parties dependent on Muslim votes control their Hindu supporters and repress violence if it occurs.

This is exactly what we would expect to find. Parties will respond, at the very least on matters of life and death, to those who vote for them and will understand that they will lose those voters if they neglect their vital interests. The quest for a conciliatory electoral system comes down to these tendencies to align the incentives of politicians with the cause of interethnic moderation.

Acknowledgements The author acknowledges gratefully the assistance of the Eugene T. Bost, Jr., Research Professorship of the Cannon Charitable Trust No. 3, at Duke Law School, which facilitated the preparation of this article. The author is also grateful for the research assistance of Ong Kian Ming and for comments from Scott DeMarchi.

\footnotetext{
${ }^{11}$ See also Elliott's (2003: 16) critique of STV in Northern Ireland: "The question could be asked whether an electoral system which maximises communal choice and ensures so little dependence on the other community for success fits the current needs in Northern Ireland." 


\section{References}

Annan, K. (2004). The comprehensive settlement of the Cyprus problem. New York: United Nations.

Baaklini, A.I. (1976). Legislative and political development: Lebanon, 1842-1972. Durham, N.C.: Duke University Press.

Bean, C. (1986). Electoral law, electoral behaviour, and electoral outcomes: Australia and New Zealand compared. Journal of Commonwealth and Comparative Political Studies, 24, 57-73.

Bean, C. (1997). Australia's experience with the alternative vote. Representation, 34, 103-110.

De Borda Institute for the Promotion of Inclusive Voting Procedures (1998). Electoral Systems in Bosnia, unpublished paper, Belfast.

Elliott, S. (2003). North Vote Sees Over 80 percent of Transfers Stay within Party. Irish Times. December 1, 2003 , p. 16.

Fraenkel, J., \& Grofman, B. (2004). A neo-Downsian model of the alternative vote as a mechanism for mitigating ethnic conflict in plural societies. Public Choice, 121, 487-506.

Fraenkel, J., \& Grofman, B. (2006a). Does the alternative vote foster moderation in ethnically divided societies? Comparative Political Studies, 39, 623-651.

Fraenkel, J., \& Grofman, B. (2006b). The failure of the alternative vote as a tool for ethnic moderation in Fiji: A rejoinder to Horowitz. Comparative Political Studies, 39, 663-666.

Fraenkel, J., \& Grofman, B. (2007). The merits of Neo-Downsian modeling of the alternative vote: A reply to Horowitz. Public Choice, 133(1-2), 1-11.

Graham, B.D. (1962). The choice of voting methods in federal politics. Australian Journal of Politics and History, 8, 164-181.

Horowitz, D.L. (1989). Incentives and behavior in the ethnic politics of Sri Lanka and Malaysia. Third World Quarterly, 11(4), 18-35.

Horowitz, D.L. (1990). Ethnic conflict management for policymakers. In Montville, J.V. (Ed.), Conflict and Peacemaking in Multiethnic Societies. Lexington, MA.: Lexington Books.

Horowitz, D.L. (1991). A democratic South Africa? Constitutional engineering in a divided society. Berkeley: University of California Press.

Horowitz, D.L. (2000a). Ethnic groups in conflict. Berkeley: University of California Press.

Horowitz, D.L. (2000b). Constitutional design: An oxymoron? In Shapiro, I. \& Macedo, S. (Eds.), Designing Democratic Institutions, Nomos XLII (pp. 253-284). New York: NYU Press.

Horowitz, D.L. (2003). Electoral systems: A primer for decision makers. Journal of Democracy, 14(4), 115127.

Horowitz, D.L. (2004). The alternative vote and interethnic moderation: A reply to Fraenkel and Grofman. Public Choice, 121(3-4), 507-516.

Horowitz, D.L. (2006). Strategy takes a holiday: Fraenkel and Grofman on the alternative vote. Comparative Political Studies, 39(5), 652-662.

International Crisis Group (1998). Changing the logic of Bosnian politics. ICG Discussion Paper on Electoral Reform. Sarajevo: ICG.

International Crisis Group (1999). Breaking the mould: Electoral reform in Bosnia and Hercegovina. Sarajevo: ICG Europe Report No. 56.

Jaensch, D., \& Mathieson, D.S. (1998). A plague on both your houses: Minor parties in Australia. Sydney: Allen \& Unwin.

Johnson, R.J. (1984). Seats, votes, redistricting, and the allocation of power in electoral systems. In Lijphart, A. \& Grofman, B. (Eds.), Choosing an Electoral System. New York: Praeger.

Marks, G., \& Bean, C. (1992). Sources of electoral support for minor parties: The case of the Australian Democrats. Electoral Studies, 11, 311-333.

Moon, E. P. (1997). Single non-transferable vote methods in Taiwan in 1996. Asian Survey, 37, $652-668$.

Premdas, R. (1978). Papua-New Guinea: The first general elections after independence. Journal of Pacific History, 13, 77-90.

Reilly, B. (2002). Political engineering and party politics in Papua New Guinea. Party Politics, 8, 701-718.

Reilly, B. (2001). Democracy in divided societies: Electoral engineering for conflict management. Cambridge: Cambridge University Press.

Sisk, T.D. (1996). Power sharing and international mediation in ethnic conflicts. Washington, D.C.: United States Institute of Peace.

Wilkinson, S. (2004). Votes and violence: Electoral competition and ethnic riots in India. Cambridge: Cambridge University Press.

Wolfers, E.P. (1968). The elections - II. New Guinea, 3, 8-31. 